\title{
Competitive Action and Response in Global Marketplace: The Drivers and Consequences
}

\author{
Eon-Seong Lee*
}

\begin{abstract}
This study aims to develop a competitive dynamics model of container shipping liners, one which examines how inter-firm network embeddedness would affect inter-firm rivalry such as the likelihood of a competitive action of a focal firm and the likelihood of its rivals' response and how the inter-firm rivalry then has an influence on the market share of the focal firm. Structural and relational network embeddedness between a focal firm and its competitors would be investigated as drivers of the likelihood of the competitive action and response. The theoretical framework on the relationship between network embeddedness, inter-firm rivalry and market share in the liner shipping industry will be developed and relevant propositions are then suggested in relation to the model. This attempt may provide meaningful insights for managers and academic researchers into the key factors which affect the inter-firm rivalry between shipping liners and may also detail the impact of inter-firm rivalry on the focal firm's market share. This research would therefore contribute to the development of the competitive strategy of container shipping companies so as to help them strategically manage their rivals' competitive behaviors and maximize their market share.
\end{abstract}

Key Words: Shipping liners, Competitive Action and Response, Network Embeddedness, Market share

\footnotetext{
* Maritime and Logistics Management Department, Australian Maritime College, University of Tasmania, Locked Bag 1397, Newnham, Launceston, TAS7248, Australia. Email:e.lee@amc.edu.au
} 


\section{INTRODUCTION}

The global business environment in the container shipping liner industry has become much more dynamic and inter-firm competition between shipping liners is very intense. In order to survive in the dynamic and uncertain environment, shipping liners are engaged in a constant business battle with one another. Therefore, the companies must know their competitors' and strategy and have knowledge of the drivers of competitive rivalry in order to successfully compete with their rivals and improve their competitive advantages. In this sense, competitor analysis has become a central strategic consideration for container shipping liners. One of the most crucial issues of the competitor analysis would be to understand a competitive dynamics of the industry, which involves the identification of a firm's rivals and prediction of the likelihood of competitive action and response of the firm and its rivals. This analysis of the competitive dynamics is vital for the shipping liner industry, because it may have a significant influence on the performance of shipping liners (Chen, 1996; Tsai et al., 2011).

Scholars in the shipping competition field have attempted to identify the competition structure or competitive conditions of the shipping liner industry (Fusillo, 2006; Sys et al., 2011), as well as to investigate various ways to effectively compete and improve the competitive advantages of shipping companies (Midoro et al., 2005). However, despite its significance, there have been few attempts to systematically analyze the competitive dynamics of the industry by identifying the factors which affect a shipping liner and its competitors' behaviors, e.g. competitive action of a shipping liner and responses of its rivals. In addition, scholars have not investigated the impact of these competitive dynamics on shipping liners' performance. This research gap may generate the following research questions (RQs).

\section{RQ1: What are key factors which affect the competitive behaviors of shipping liners?}

\section{RQ2: How would the competitive behaviors of shipping liners affect their organizational performance?}

In order to answer the above research questions, this paper adopts a network embeddedness perspective, which suggests that a focal firm's differentiated position within a network which consists of multiple connections between a shipping liner and its rivals would affect competitive behaviors of the focal firm and the rivals, because, due to the constraints of their own asset, the companies in the network are not free to undertake any competitive action, but instead are influenced by their rivals' behaviors which are 
embedded within the same network (Gnyawali and Madhavan, 2001). This study then develops a competitor dynamics model of container shipping liners, one which examines how inter-firm network embeddedness would affect inter-firm rivalry such as the likelihood of a competitive action of a focal firm and the likelihood of its rival's response and how the inter-firm rivalry then has an influence on the market share of the focal firm. The theoretical framework on the relationship between network embeddedness, inter-firm rivalry and market share will be developed and relevant propositions are then suggested in relation to the model. Finally, academic and managerial implications of this paper are then discussed.

\section{THEORETICAL BACKGROUND}

\subsection{Competitive Dynamics}

Inter-firm rivalry is characterized as being dynamic in its nature (Chen, 1996), as "a competitive event would occur by combination of an action and a reaction between rival firms" (Grimm et al., 2006, p. 89). There are two key indicators in addressing competitive dynamics between companies: they are the likelihood of a firm's initiating a competitive action and the likelihood of a competitor's responding to that action (Chen, 1996; Grimm et al., 2006).

The competitive action is referred to as "a specific and observable competitive move, such as a new product introduction, advertising campaign, or price cut, initiated by a firm to improve or defend its relative competitive position" (Grimm et al., 2006, p. 87). A competitive response is defined as "market move taken by a firm to counteract the initial competitive action of a rival" (Grimm et al., 2006, p. 89). The action and response dynamics may have an influence on the firms' performance (Chen and Hambrick, 1995). If a firm initiates a stronger competitive attack, it would lead to the greater market share (Chen and MacMillan, 1992; Young et al., 1994). If the competitor who has been attacked responds to the attack more aggressively, the performance of the attacking firm would be threatened by the response; and the weaker the response of the competitor, the greater the attacking firm's performance (Chen, 1996). Therefore, firms that initiate competitive attacks tend to gain greater benefits by preventing their competitors from responding to those actions (Gnyawali and Madhavan, 2001). In this sense, understanding and managing the likelihood of action and response would matter in order to improve firms' competitive advantages. 
The above previous findings are applicable to the shipping liner industry where the global competition of shipping liners get fierce more and more and the firms' action and responses which are being made in a more various and dynamic way would become one of the most significant issues for the shipping liners to survive in the industry.

\subsection{Network Embeddedness}

Existing studies commonly regard a social network as a pattern or a set of social relationships among various forms of organizations (e.g. firms or institutions) (Gulati, 1998; Nahapiet and Ghoshal, 1998; Kogut, 2000). Near common consensus agrees that firms could acquire greater resources, such as information, knowledge or other types of assets, e.g. skills or financial assets, from a social co-operative network where they are embedded, since the network provides timely chances to get valuable knowledge and resources (Gulati, 1999; Rowley et al., 2000). A different position in a network brings varying opportunities to achieve informational priorities and competitive advantages (Chen and Miller, 1994). This view has been referred to as the network embeddedness perspective. Network embeddedness perspective indicates two types of mechanisms in order to describe the differential resource-based benefits: structural and relational embeddedness (1992; Gulati, 1998).

Structural embeddedness perspective acknowledges that the structure of a social network creates a number of opportunities to acquire external resources and a superior structural position in a network enables firms to rapidly share information and assets (Gnyawali and Madhavan, 2001). The network density, which is one of the most popular indicators of the structural embeddedness, is referred to as the extent to which the ties among the actors are inter-connected in a network. The greater the ties by which network entities are connected, the denser the network it is. A dense network has a positive impact on actors' behaviors and outcomes. Firstly, it facilitates faster and more efficient flows of resources and enables actors to share and distribute resources with each other through the many interconnections within the network (Coleman, 1990; Valente, 1995). Secondly, behaviors or business habits of actors in a highly dense network can be easily known, since the actors are all well acquainted with each other. That reputation effect may serve as an effective tool to monitor or sanction other firms' business actions (Granovetter, 1985; Chen and Miller, 1994). Finally, as actors in a dense network interact with each other frequently and closely, they can more easily build up trust, norms and shared behavioral routine (1990). Consequently, an actor in the higher density network is exposed to a rich flow of resources and has more opportunities to develop an inter-firm governance mechanism, 
which in turns leads to enormous informational advantages for the actor.

Relational embeddedness is referred to as how entities are closely related with each other (Gulati, 1998). Literature on network embeddedness highlights tie strength as the most important indicator of relational network embeddedness (Granovetter, 1973; Uzzi, 1997; Rowley et al., 2000). Granovetter (1973) defines tie strength as "a combination of the amount of time, the emotional intensity, the intimacy (mutual confiding) and the reciprocal services which characterize the tie" (p. 1361). Uzzi (1996) suggests several notable benefits of strong ties. Firstly, trust between organizations can be developed by strong network relationships, which then facilitate the exchange of valuable resources and information that are difficult to transfer in the market. Secondly, strong and close ties can promote in-depth and two-way communication. This allows actors to share knowledge that is more proprietary and more tacit (Krackhardt, 1992; Uzzi, 1996). In addition, a strong relationship accelerates social learning among which can then mitigate environmental uncertainty and enable firms to respond to new environments (Kraatz, 1998). As firms with strong network ties can communicate with each other in a deeper and more open way, they can get more prompt and proper feedback from each other, which helps to effectively and efficiently coordinate the different functions of all the actors. Such routines also enable firms to correct and solve mutual problems more easily. Consequently, the strong tie is positively related to firm performance through the aforementioned benefits (Uzzi, 1997).

\subsection{Competition and Co-operative Network in the Shipping Liner Industry}

The container shipping sector accounts for much of the world seaborne trade. Over the last decade, worldwide container shipping volumes have steadily increased. This growth is due to the sharp increase in containerized international trade. According to a report by the United Nations Conference of Trade and Development (UNCTAD) (2007), "the international trade derived from containerization have rapidly increased at an average annual rate of 11 percent since 2001 to reach 88 million TEU in year 2005 and over 70 percent of the value of world international seaborne trade is being moved in containers." ( $p$. 20). The sharp rise of container movement has led to the rapid growth in shipping volumes carried.

Today's shipping lines are enforced to offer higher frequencies, more flexible shipping schedules, reliable and safe sailings and lower freight rates (Notteboom, 2006). The shipping lines are also required to be effectively integrated in the logistics integration system by moving goods that are geographically scattered as quickly as possible. In order to fulfill the demands of their customers, shipping lines need to develop an efficient liner 
service network with their customers, other carriers, suppliers, manufacturers and final customers; and they also need to use a well developed information system to share the appropriate transportation information with the market participants and to coordinate multiple linked relationships.

Accordingly, competition in a shipping industry is intense and in particular, the competition among shipping lines which have similar shipping routes is very tough. As firms of various sizes (e.g. large, medium and small firms) co-exist in the shipping industry, the competition among firms of a similar size tends to be more intensive (Panayides and Gray, 1999).

Recently, in order to survive such intense competition in the shipping industry, shipping liners have become proactively engaged in various types of co-operative networks, in which shipping companies are multiply connected by cooperating between rivals. Strategic alliances, shipping conferences and vessel sharing agreements are good examples of this co-operative network between rivals (Frankel, 1982; Brooks, 2000). Global strategic alliances are the most popular form of the shipping lines' co-operative network. For example, The Grand Alliance consists of Hapag-Lloyd, Nippon Yusen Kaisha (NYK) and Orient Overseas Container Line (OOCL), who plan to extend their co-operative relationship up to 2017. Cosco/K-Line/Yangming/Hanjin Alliance and New World Alliance are also one of the most popular strategic alliances in the shipping industry. In 2005, Maersk Sealand acquired P\&O Nedlloyd, which was a member of the Grand Alliance. Such strategic alliances aim primarily to improve service qualities by increasing the number of ports of call, broadening the range of shipping routes and providing a world-wide network of shipping services. Shipping lines also attempt to realize cost saving, increase their market share, share capital investments and reduce industry risks throughout the strategic co-operative network (Yoshida et al., 2004).

Shipping conferences are collaborative organizations of shipping lines which provide similar shipping routes and the lines cooperate to fix the freight rates in order to reduce competition among themselves and protect their business. Another co-operative form is the vessel sharing agreement, which aims to fix the amount of vessel capacity and share the carriers' slot per trip between shipping lines. For example, two shipping lines who are partners for vessel sharing along the same route, fix the vessel capacity to efficiently share their cargoes in order to maintain optimized use of the vessels, offer various time schedules in a more flexible way and deliver the cargoes on time (Lei et al., 2008).

Yet despite the above efforts being taken to survive in the industry, shipping lines are still confronted with a lot of strategic tasks in flexibly responding to the volatile demands of their customers and in maximizing their profits under the dynamically changing business 
environments. They also need to design and implement optimal strategies in order to outperform their competitors, thereby gaining competitive advantages as well as enhancing their performance. The competitive strategies to help shipping liners effectively manage the global competitive dynamics and enhance their organizational performance will be discussed in the next section.

\section{MODEL AND PROPOSITIONS}

Existing studies addressed that the competition dynamics, i.e. the likelihood of action and the likelihood of response, is influenced by the way the firm is embedded in inter-firm network relationships with other competitors in the same industry (Gnyawali and Madhavan, 2001; Tsai et al., 2011). It has been also revealed that the aforementioned competitive dynamics would help a focal firm to outperform a rival by allowing them to gain more market share relative to that of their rivals (Chen and MacMillan, 1992; Ferrier, 2001). Having been based on the literature review, a conceptual model is developed by applying the aforementioned theories to the competition between shipping liners, as seen in the Figure 1. The model shows how network embeddedness between shipping liners influences competitive behaviors and examines whether the competitive dynamics would help the companies to improve their performance.

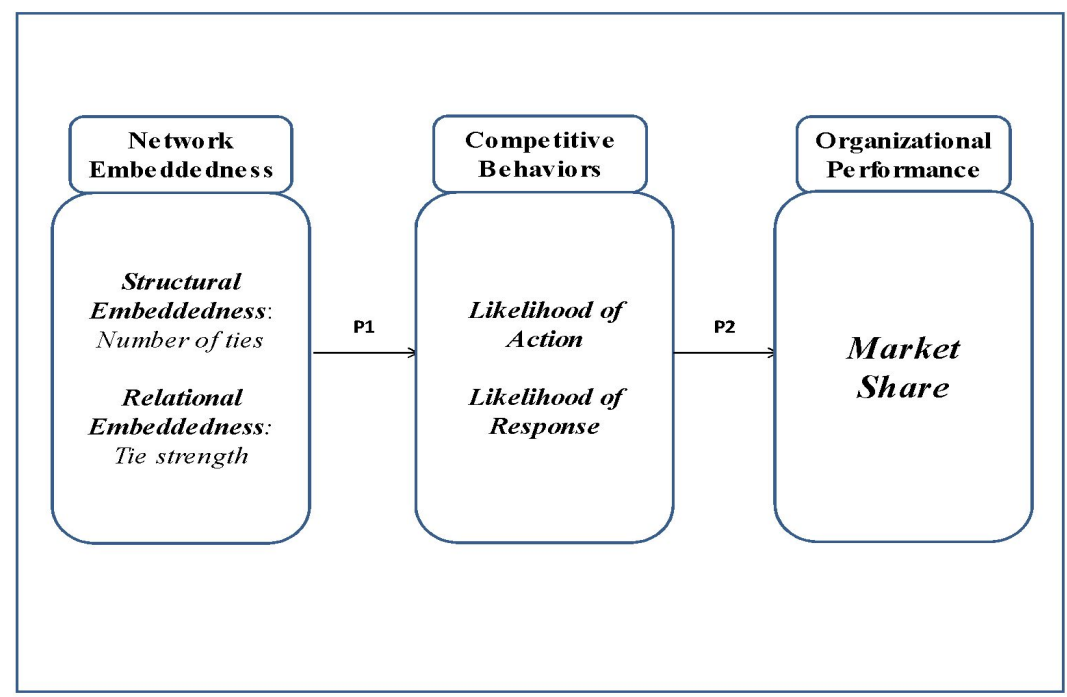

Figure 1.

Conceptual Framework 


\subsection{Network Embeddedness and Competitive Behaviors}

Today's shipping liners are interacting with their competitors in different markets and they are confronting competitions with the same rivals in various markets simultaneously. Shipping liners may not be free to undertake competitive action or reaction as an independent entity, but are influenced by these inter-firm network relationships (Tsai et al., 2011). The structural and relational embeddedness of the network to which the shipping liners belong may therefore affect competitive behaviors of the network players. The structural network embeddedness can be measured as the extent to which a great number of ties are actually observed in the network (Madhavan et al., 1998; McEvily and Zaheer, 1999). If a shipping liner has a great number of cooperative connections with their competitors by being embedded in a dense network, they could get more chances to access other rivals' information and knowledge (1976). Furthermore, the shipping liner could have greater access to external assets, such as technology and management skills or know-how from other entities in the network. The relational network embeddedness can be measured as the closeness of the relationships with other network entities, i.e. frequency of interaction in the network and the extent of mutual commitment with other network players (Uzzi, 1997; Yi-Renko et al., 2001). The strength of ties may also facilitate the informational and asset related superiority of a shipping liner. Strong relationships with other players in a network can promote in-depth, two way communication and facilitate the exchange of solid information between organizations (Krackhardt, 1992; Uzzi, 1997; Song and Lee, 2012).

In the Korean shipping industry, for example, it was revealed that shipping liners which establish a high number of and strong relationships with other entities in the network acquire more useful information and know-how than other companies that do not have such relationships (Song and Lee, 2012). This occurs because a high number of and strong partnerships between rivals thus enables the focal firms to easily access the common pool of knowledge and encourages them to effectively share useful information about market trends and, customer demands as well as the competitors' strategy and competitive behaviors (Gnyawali and Madhavan, 2001; Song and Lee, 2012).

The above resource-based benefits, which are achieved through the structural and relational network embeddedness as outlined above, may also influence the likelihood of shipping liners' competitive action and response. The likelihood of competitive action can be measured as the degree to which a shipping liner may initiate competitive attacks such as cutting prices, developing new shipping routes or entering new markets, operating larger vessels and providing more innovative customer services. The likelihood of competitive response can be measured as the degree to which a shipping liner that is attacked by its rival would proactively respond to those attacks, such as undertaking more aggressive price cuts 
or marketing activities, increasing $R \& D$ investments and developing the same new markets or shipping routes as their rivals (Chen, 1996; Gnyawali and Madhavan, 2001). As the shipping liner can have access to a larger set of information as a result of the benefits gained from relational and structural network embeddedness, they would come to know more about other competitors' competitive strategy and could therefore more accurately predict the effectiveness of their attack and the possible response of their rivals. This would also strengthen the focal firm's competitive capability and then facilitate feasible competitive actions of the firm (Chen, 1996; Gnyawali and Madhavan, 2001), thereby increasing the likelihood of the action of a focal firm. Inversely, if a shipping liner cannot manage to acquire adequate knowledge and assets due to the lack of sufficient number of or strong ties in the network, they may not have enough knowledge of their competitors' practices and what is going on their rivals' strategic behaviors. This may, in turn, mean that the focal firm might hesitate to initiate the attack. As a result, the likelihood of action of a focal firm would be reduced and the likelihood of attack by their competitors would, in turn, increase.

The resource and information related benefits of a focal firm which are achieved from an advantageous position within a network (i.e. greater number of and strong ties) may hinder other rivals from proactively responding to the focal firm's initial competitive action, because there are a number of resource asymmetries between the focal firm and its rivals. The informational and asset related inferiority of other rivals may create more difficulties in accurately understanding the seriousness and effects of the initial competitive action of a focal firm, as well as in promptly analysing its implications. As a result, the rivals are less likely to respond to the focal firm's attack in an appropriate and timely manner and thus the likelihood of the rivals' responses would be reduced. In turn, if a focal firm has less information on its rivals' practices and behaviors due to the lack of sufficient number of or strong ties in the network, the rival companies may have more power relative to the focal company. Consequently, the likelihood of the rival's responses would increase (Chen,1996; Gnyawali and Madhavan, 2001).

For example, in recent times some top leading global shipping liners such as Maersk, MSC, CMA CGM, Evergreen Line, etc., have established a high numbers of strong partnerships with their rivals by proactively engaging in various forms of cooperative relationships. These cooperative relationships take the form of strategic alliances and vessel sharing agreements and allow the companies to work more closely together. As a result of these partnerships, the shipping liners can acquire more knowledge about their markets and the industry, as well as their rivals' operational skills, capabilities and competitive. They can also continuously improve their competitive capabilities (Containerisation International, 2013a). These benefits have helped them to aggressively increase their fleet 
capacity despite the current tough market conditions and they have also enabled the companies to provide a better level of service by reducing price and lead time and improving service reliability, responsiveness and flexibility. As a result, the benefits gained through the network embeddedness could increase the likelihood of the companies' competitive action, or reduce the likelihood of response from their rivals (Containerisation International, 2013a; Song and Lee, 2012).

Having acknowledged the above competitive dynamics between a focal shipping liner and its competitors, the following propositions regarding the association between the network embeddedness and the likelihood of action and response are suggested.

Proposition 1: Structural and relational network embeddedness may affect the likelihood of action of a focal firm.

Proposition 1a: The greater number of ties that a focal firm has with their competitors within a network, the greater the likelihood of action of a focal firm.

Proposition 1b: The stronger ties a focal firm has with their competitors within a network, the greater the likelihood of action of a focal firm.

Proposition 2: Structural and relational network embeddedness may affect the likelihood of response of a focal firm's competitors.

Proposition 2a: The greater number of ties that a focal firm has with their competitors within a network, the less the likelihood of responses from a focal firms' rival.

Proposition 2b: The stronger ties a focal firm has with their competitors within a network, the less the likelihood of responses from a focal firm's rival.

\subsection{Competitive Dynamics and Market Share}

Existing studies have addressed that the likelihood of competitive actions and responses would affect a firm's outcomes (Smith et al., 1991; Chen and MacMillan, 1992; Chen and Hambrick, 1995). For instance, a shipping liner which could attack their rivals more quickly and frequently could gain greater market share than others who are not equally proactive (Chen and MacMillan,1992). This would be possible because the shipping liner which has a high level of the likelihood of competitive actions tends to have more experience in how to effectively carry out competitive actions, as well as in how to acquire more information on how their rivals would react to their attack (Ferrier, 2001). 
They would also have the capability to rapidly develop proper competitive tactics and prevent their rivals from proactively initiating an attack on them (Tsai, 2011). As the firm's competitive actions increase, it would help the firm to enhance its internal capabilities in terms of the development of competitive action routines and skills on how to effectively initiate attacks to their rivals and how to improve the decision-making efficiency of the competitive actions (Young et al., 1996). These benefits of the shipping liner would weaken the rivals' knowledge on when or how the firm would initiate attack, which actions will be made by the attacker and how they could effectively respond to the attacks (Ferrier, 2001). Consequently, other things being equal, a shipping liner with a high level of the likelihood of competitive actions is likely to be in an advantageous position in developing their capability to successfully win over their rivals and therefore gain more market share relative to their rivals (Tsai, 2011).

On the other hand, there is an inverse association between the likelihood of response and a firm's performance (Smith et al., 1991; Chen and Miller, 1994). For instance, a shipping liner which has a low level of the likelihood of response from its rivals would gain more benefits in terms of the following aspects. The shipping liner's rivals might have less knowledge or experiences of how to respond swiftly to the attacker's action and thus expose higher vulnerabilities to their attack. They may be less sure about how the firm's attack has been prepared and made up and what and how the potential attack would be sequenced in the future. Consequently, this would make them lose their market share (Chen and Hambrick, 1995). It is therefore argued that, other things being equal, a shipping liner with a low level of the likelihood of competitive response is likely to have more market share relative to their rivals.

For instance, global leading container shipping liners such as Maersk, MSC and CMA CGM which combined take around thirty percent out of the world total market share in the shipping liner industry, have been ranked as top three in the world and their positions have remained unchanged for several years. The key to this success lies in the fact that these companies have made a constant effort to improve their competitive capabilities by proactively joining intimate partnerships with their rivals and acquiring useful information and know-how about the market along with their competitors (Containerisation International, 2013b). These efforts have enabled them to attack their rivals in a swift and timely manner and have allowed them to accumulate organizational know-how about how to repeat the competitive actions continuously in order to further gain their market share. The organizational capabilities may have threatened the willingness of the responses to the attacks of their rivals which have less competitiveness, because the asymmetry in the resource and organizational capability between the powerful companies and their rivals may hinder the rivals from recklessly responding to them, thereby decreasing the market 
share of the rivals. Therefore, the high levels of competitive actions of the leading shipping liners and the less likelihood of their rivals' responses may have helped the leading companies to gain greater market share. On the basis of the aforementioned arguments, the following propositions are suggested:

Proposition 3a The likelihood of competitive actions of a focal firm is positively associated with its market share.

Proposition $3 b$ The likelihood of responses from a focal firm's rival is negatively associated with the focal firm's market share.

\section{DISCUSSION AND CONCLUSION}

This paper argued that a shipping liner's structural and relational position within a competitor network may generate the resource (e.g. information and assets) asymmetries between a focal firm and its competitors, thereby influencing the competitive dynamics, i.e. the likelihood of a focal firm's competitive actions and the likelihood of its rivals' responses. As a result, the focal firm's performance, i.e. market share, would be affected by the competitive dynamics, to the effect that the greater competitive action shown by a firm would entail more market share for that firm, just as a less competitive response from the focal firm's rival would also, in turn, mean more market share for the firm that initiates competition.

This paper further advances research on the shipping liners' strategic management field by specifying the following new points: firstly, it may provide a meaningful insight into systematically understanding how inter-firm network relationship affects an inter-firm rivalry between shipping liners and furthermore how this inter-firm rivalry may influence the focal firm's organizational performance. This research would therefore contribute to the development of the competitive strategy of container shipping companies so as to help them strategically manage various relationships with their rivals and maximize their market share. Secondly, this research is also academically valuable, as this attempt is the first work to thoroughly analyze the competition dynamics in the container shipping industry. Existing studies relatively neglected the role of a firm's different position within a network in enabling them to effectively compete by helping gain greater resource-based benefits, thereby affecting the probability of competitive actions and responses. This paper, in this regard, could complement the aforementioned academic lack by highlighting the way on how to strategically coordinating inter-organizational network embeddedness in order to 
survive in the fiercely competitive business environments in the shipping liner industry. Finally, this attempt has been based on existing renowned literature on international business and strategic management research fields and this adoption would be indispensable for the current shipping business research, given the fact that shipping companies are key players within the global business unit (GBU).

From a managerial implication stance, today's shipping lines are still confronted with problems that must be solved under the dynamically changing and unstable world economy. For example, as the recent decreased container volumes in global trade, affected by the global economic crisis, have rarely shown an upward tendency, ship fleets are over supplied and consequently freight rates continuously decrease. Furthermore, the increase in shipping alliances and mergers and acquisitions between leading global shipping lines has caused a concern that the shipping industry would become an oligopoly. Under these current conditions, better understanding competitive dynamics and effectively managing inter-rival relationships is even more significant. In this sense, this paper could provide shipping managers with meaningful strategic insights on such issues. In addition, shipping lines need to pay greater attention to market trends and accurately forecast the market situation from a medium- and long-term perspective. Shipping companies should also respond to the environmental threats and administrate managerial risks in a more enthusiastic, flexible and effective manner. Those activities can be achieved by acquiring a superior amount of information. This information superiority and relative advantages could be driven from the firm's advantageous network positions, i.e. establishing a high number of strong ties in the network. Therefore, it is more necessary that shipping liners should recognize the need for viewing network relational and structural embeddeness as a significant strategic "lever" which help them refine their competitive behaviors and enhance their performance (Gnyawali and 2001).

As this research has focused only on the theoretical framework, future research needs to further empirically analyze the conceptual arguments of this paper. The empirical analysis could be conducted by employing an exploratory case study in order to identify the patterns in the shipping liner industry in relation to this research model, or by establishing and testing relevant research hypotheses empirically using survey questionnaire and statistical methods. 


\section{REFERENCES}

Brooks, M. (2000) Sea Change in Liner Shipping: Regulation and Managerial Decision-Making in a Global Industry, Pergamon, New York.

Chen, M. and Miller, D. (1994) "Competitive Attack, Retaliation and Performance: An Expectancy-Valence Framework”, Strategic Management Journal, 15(1), 85-102.

Chen, M-J. (1996) "Competitor analysis and Interfirm Rivalry: Toward a Theoretical Integration, Academy of Management Journal, 21(1), 100-134.

Coleman, J. S. (1990), Foundation of Social Theory, Harvard Business School Press, Boston.

Containerisation Interanational (2013a), July 2013, Informa Plc, London.

Containerisation Interanational (2013b), November 2013, Informa Plc, London.

Chen, M.-J. and Hambrick D. C. (1995) "From Entry Barriers to Mobility Barriers", Quarterly Journal of Economics, 9, 241-261.

Chen, M-J. and MacMillan, I. C. (1992) "Nonresponse and Delayed Response to Competitive Moves: The Roles of competitor Dependence and Action Irreversibility" Academy of Management Journal, 35(3), 539-570.

Chen, M-J. and Hambrick, D. C. (1995) "Spped, Stealth and Selective Attack: How Small Firms Differ from Large Firms in Competitive Behavior" Academy of Management Journal, 38(2), 453-482.

Ferrier, W. J. (2001) "Navigating the Competitive Landscape: The Drivers and Consequences of Competitive Aggressiveness", Academy of Management Journal, 44(4), 858-877.

Ferrier, W. J. and Smith, K. G. (1999) "The Role of Competitive Action in Market Share Erosion and Industry Dethronement: A Study of Industry Leaders and Challengers", Academy of Management Journal, 42(4), 372-388.

Frankel, E. G. (1982), Management and Operations of American Shipping, Auburn House Publishing Company, Boston.

Fusillo, M. (2006), "Some Notes on Structure and Stability in Liner Shipping", Maritime Policy and Management, 33(5), 463-475.

Gnyawali, D. R. and Madhavan, R. (2001) "Cooperative Networks and Competitive dynamics: A structural Embeddedness Perspective" Academy of Management Journal, 26(3), 431-445.

M. (1973), "The Strength of Weak Ties", American Journal of Sociology, 78(5), 1360-1380.

Granovetter, M. (1992), Problems of Explanation in Economic Sociology, in Nohria, N. 
and Eccles, R. C. (eds.), Networks and Organizations, Harvard Business School Press, Boston, pp. 25-56.

Grimm, C. M., Lee, H. and Smith, K. G. (2006) Strategy as Action: Competitive Dynamics and Competitive Advantage, Oxford University Press, New York.

Gulati, R. and Singh, H. (1998), "The Architecture of Cooperation: Managing Coordination Costs and Appropriation Concerns in Strategic Alliances", Administrative Science Quarterly, 43(4), 781-814.

Kogut, B. (2000), "The Network as Knowledge: Generative Rules and the Emergence of Structure, Strategic Management Journal", 21(3), 405-425.

Krackhardt, D. (1992), "The Strength of Strong Ties: The Importance of Philos in Organizations," in Nohria, N. and Eccles, R. (eds.), Networks and Organizations: Structure, Form and Action, Harvard Business School Press, Boston, pp. 216-239.

Kraatz, M. S. (1998) "Learning by Association? Interorganizational Networks and Adaptation to Environmental Change", Academy of Management Journal, 41(6), 621-643.

Lai, K.-H., Ngai, E. W. T. and Cheng, T. C. E. (2002) "Measures for Evaluating Supply Chain Performance in Transport Logistics", Transport Research Part E, 38(7), 439-456.

Madhavan, R, Koka, BR and Prescott, H. E. (1998) 'Networks in Transition: How Industry Events (Re)shape Interfirm Relationships', Strategic Management Journal, 19(5), pp. 439-459.

McEvily, B and Zaheer, A. (1999) "Bridging Ties: A Source of Firm Heterogeneity in Competitive Capabilities', Strategic Management Journal, 20(12), 1133-1156.

Midoro, R., Musso, E. and Parola, F. (2005) "Maritime Liner Shipping and the Stevedoring Industry: Market Structure and Competition Strategies", Maritime Policy and Management, 32(2), 89-106.

Notteboom, T. E. (2006) "The Time Factor in Liner Shipping Services", Maritime Economics and Logistics, 8(1), 19-39.

Panayides, P. M. and Gray, R. (1999) “An Empirical Assessment of Relational Competitive Advantage in Professional Ship Management", Maritime Policy and Management, 26(2), 111-125.

Rowley, T., Behrens, D. and Krackhardt, D. (2000) "Redundant Governance Structures: An Analysis of Structural and Relational Embeddedness in the Steel and Semiconductor Industries", Strategic Management Journal, 21(3), 369-386.

Smith, K.G., Ferrier, W. and Ndofor, H. (2001) Competitive dynamics Research: Critique and Future Directions, in Handbook of Strtegic Management, (eds.) Hitt. M., Freeman, R. and Harrison, J., 315-361, Blackwell, London. 
Song, D-W. and Lee, E-S. (2012) "Coopetitive Networks, Knowledge Acquisition and Maritime Logistics Value", International Journal of Logistics Research and Applications, 15(1), 15-35.

Sys, C., Meersman, H. and Van de Vooorde, E. (2011), A non-structural test for competition in the container liner shipping industry, Maritime Policy and Management, 38(3), 219-234.

Tsai, W., Su, K-H. and Chen, M-J. (2011) "Seeing Through the Eyes of a Rival: Competitor Acumen Based on Rival-Centric Perceptions", Academy of Management Journal, 54(4), 761-778.

UNCTAD (2007), Review of Maritime Transport 2007, United Nations, New York.

Uzzi, B. (1996), "The Sources and Consequences of Embeddedness for the Economic Performance of Organizations: The Network Effect", American Sociological Review, 61(5), 674-698.

Uzzi, B. (1997), "Social Structure and Competition in Interfirm Networks: The Paradox of Embeddedness", Administrative Science Quarterly, 42(2), 35-67.

Valente, T. W. (1995), Network Models of the Diffusion of Innovation, Hampton Press, New Jersey.

Young, G., Smit, K. and Grimm, C. (1996) ““'Austrian” and Industrial Organization Perspectives on Firm-Level Competitive Activity and Performance", Organization Science, 7, 243-254.

Yi-Renko, H., Autio, E. and Sapienza, H. J. (2001) "Social Capital, Knowledge Acquisition and Knowledge Exploitation in Young Technology based Firm", Strategic Management Journal, 22(7), 587-614.

Yoshida, S., Yang, J. H. and Kim, K. H. (2004) "Network Economics of Global Alliances in Liner Shipping: The Case of Japanese Liner Shipping Companies", in World Shipping and Port Development, (eds.) Lee, T.-W. and Cullinane, K. Palgrave Macmillan, New York, pp. 36-49. 